Article

\title{
Some Escape Time Results for General Complex Polynomials and Biomorphs Generation by a New Iteration Process
}

\author{
Lateef Olakunle Jolaoso ${ }^{1}$ (D) and Safeer Hussain Khan ${ }^{2, *} \mathbb{D}$ \\ 1 Department of Mathematics and Applied Mathematics, Sefako Makgatho Health Sciences University, \\ P.O. Box 94, Medunsa 0204, South Africa; lateef.jolaoso@smu.ac.za \\ 2 Department of Mathematics, Statistics and Physics, Qatar University, Doha 2713, Qatar \\ * Correspondence: safeer@qu.edu.qa
}

Received: 3 November 2020; Accepted: 25 November 2020; Published: 5 December 2020

\begin{abstract}
Biomorphs are graphic objects with very interesting shapes resembling unicellular and microbial organisms such as bacteria. They have applications in different fields like medical science, art, painting, engineering and the textile industry. In this paper, we present for the first time escape criterion results for general complex polynomials containing quadratic, cubic and higher order polynomials. We do so by using a more general iteration method also used for the first time in this field. This also generalizes some previous results. Then, biomorphs are generated using an algorithm whose pseudocode is included. A visualization of the biomorphs for certain polynomials is presented and their graphical behaviour with respect to variation of parameters is examined.
\end{abstract}

Keywords: bimorphs; iteration; escape criterion

\section{Introduction}

Historically, British writer Geoffrey Grigson in 1935 coined the term biomorphism in the context of art [1]. Biomorphs are also used in painting [2], architecture [3,4] and industrial design [5,6]. Biomorph may be defined as a painted, drawn, or sculptured free form or design suggestive in shape of a living organism, especially an ameba or protozoan. The concept of fractal generations has a rich history in computer graphics. In 1918, Gaston Julia introduced the Julia set using a simple iterative process to generate interesting fractals. Interest in this concept has grown significantly due to the visual beauty, complexity and self similarity of the Julia sets; see for instance [7-11]. In 1975, Benoit Mandelbrot [12] extended the work of Gaston Julia and introduced a new set of connected Julia sets called Mandelbrot set. The Mandelbrot and Julia sets have been studied for quadratic $[9,11,13,14]$, cubic $[9,14-17]$, and higher degree polynomials [18] under Picard orbit, which is a one-step iteration process.

Recently, Rani and Kumar [19,20] studied a one-step Mann iteration process for generating Julia and Mandelbrot sets for a class of $n$ degree complex polynomials. Their work was further extended by Chauhan et al. [21] by studying a two-step Ishikawa iteration for generating relative superior Julia and Mandelbrot sets. Moreover, Chauhan et al. [22] studied the two-step Ishikawa iteration process for non-integer values polynomials for generating relative superior Julia and Mandelbrot sets. Furthermore, Ashish and Rani [23] investigated three-step Noor iterations for generating Julia and Mandelbrot sets. Very recently, many others have proposed other forms of iterations for generating different Julia and Mandelbrot sets; see, for instance, [24] and references therein.

In 1986, Pickover introduced a modification of the Julia sets called biomorphs [25]. Though the biomorphs were accidentally found by Pickover, they have found applications in biology and art (see [26-28]). We note that there are very few results on iterative methods for generating biomorphs 
in the literature. In 2016, Gdawiec et al. [29] introduced a new set of biomorphs by using Pickover algorithm with Mann and Ishikawa iterations. It was found that the changes in the iteration process caused varying dynamics and behaviour of the generated biomorphs with interesting artistic features compared to the ones generated using the Pickover algorithm with the Picard orbit.

In this paper, we employ a new general iteration with the Pickover algorithm and obtain a new set of biomorphs. First, we present for the first time escape criterion results for general complex polynomials containing quadratic, cubic and higher order polynomials. We then combine the new general iteration with the Pickover algorithm and obtain and examine new sets of biomorphs with interesting artistic features.

The rest of the paper is organized as follows. In Section 2, we recall some basic definitions and iterative processes necessary for our study. In Section 3, we present the escape criterion results for general complex polynomials. We obtain as corollaries such results for quadratic, cubic and higher order polynomials. Even our corollary generalizes some previous results. In Section 4, we present our algorithm and biomorphs generated by the algorithm. In Section 5 , we give some concluding remarks and possible future work in this direction.

\section{Preliminary Results and Iteration Methods}

Let $P(x)$ be a function in a complex plane $\mathbb{C}$ and $x_{0} \in \mathbb{C}$ be a starting point. Given $x_{k} \in \mathbb{C}$, the recursive formula

$$
x_{k+1}=P\left(x_{k}\right) \quad k \geq 0,
$$

is called Picard iteration or orbit $O\left(x_{0}\right)$ of the starting point $x_{0}$. For a given function $P$, the behaviour of the orbit $O\left(x_{0}\right)$ defined by the sequence $\left\{x_{k}\right\}$ depends on the selected $x_{0}$ value. The set of points for which the orbit is chaotic is called the Julia set.

The behaviour of the orbit $O\left(x_{0}\right)$ defined by the set or sequence of points $\left\{x_{k}\right\}$ is studied using an escape-time algorithm. An escape-time algorithm terminates an iterating formula when either the size of the positive orbit $O\left(x_{0}\right)$ exceeds a selected bailout real value $\varepsilon$ or an iteration limit $\delta$ is reached. When any of these occurs, the pixel corresponding to the starting point $x_{0}$ is coloured according to the final or last iteration number. In the case of a given Julia set, the classical approach obtains the magnitude $\left|x_{k}\right|$ of $\left\{x_{k}\right\}$ or Euclidean norm of the orbit $O\left(x_{0}\right)$ :

$$
\left|x_{k}\right|=\sqrt{\operatorname{Re}\left(x_{k}\right)^{2}+\operatorname{Im}\left(x_{k}\right)^{2}},
$$

where $\operatorname{Re}\left(x_{k}\right)$ and $\operatorname{Im}\left(x_{k}\right)$ are the real and imaginary parts of $x_{k}$, respectively. The classical convergence criterion of the escape-time algorithm is given by

$$
\sqrt{\operatorname{Re}\left(x_{k}\right)^{2}+\operatorname{Im}\left(x_{k}\right)^{2}} \leq \varepsilon, \quad \varepsilon \in \mathbb{R} .
$$

Pickover relaxed (1) and introduced the following criterion.

$$
\left(\left|\operatorname{Re}\left(x_{k}\right)\right| \leq \varepsilon\right) \vee\left(\left|\operatorname{Im}\left(x_{k}\right)\right| \leq \varepsilon\right) .
$$

The image obtained by his criterion is called biomorph: resembling unicellular and microbial organisms. This leads to a new research consideration of the Julia sets using (2) instead of (1); see for instance [26-29].

Definition 1. The set of all points in $\mathbb{C}$ for which the orbits do not converge to a point at infinity is called a filled Julia set denoted by $F_{P}$, i.e.,

$$
F_{P}=\left\{x \in \mathbb{C}:\left\{\left|P\left(x_{k}\right)\right|_{k=0}^{\infty} \quad \text { is bounded }\right\}\right.
$$


The Julia set of $P$ denoted by $J_{P}$ is the boundary of filled Julia set, i.e., $J_{P}=\partial F_{P}$.

Definition 2. The Mandelbrot set $M$ is the set of all parameters $r \in \mathbb{C}$ for which the Julia set $J_{Q_{r}}$ where $Q_{r}(x)=x^{2}+r$ is connected, i.e.,

$$
M=\left\{r \in \mathbb{C}: J_{Q_{r}} \quad \text { is connected }\right\} .
$$

Equivalently

$$
M=\left\{r \in \mathbb{C}:\left\{\left|Q_{r}\left(x_{k}\right)\right|\right\} \not \rightarrow \infty \text { as } k \rightarrow \infty\right\} .
$$

The general escape criterion for Julia and Mandelbrot sets using the Picard orbit is given by the following result (see, e.g., [14]).

Theorem 1. Given $Q_{r}(x)=x^{2}+r$ where $x, r \in \mathbb{C}$, if there exists $k \geq 0$ such that

$$
\left|Q_{r}\left(x_{k}\right)\right|>\max \{|r|, 2\},
$$

then $Q_{r}\left(x_{k}\right) \rightarrow \infty$ as $k \rightarrow \infty$.

The term $\max \{|r|, 2\}$ is called the escape radius threshold for generating the Julia and Mandelbrot sets using the Picard orbit for quadratic, cubic and general polynomials.

The following iterations were introduced as generalizations of the Picard iteration for approximating the fixed point of a mapping $T: \mathbb{C} \rightarrow \mathbb{C}$ :

(i) Mann iteration [30]: given $x_{0} \in \mathbb{C}$, then

$$
x_{k+1}=(1-\alpha) x_{k}+\alpha T x_{k}, \quad k \in \mathbb{N},
$$

where $\alpha \in(0,1]$

(ii) Ishikawa iteration [31]: given $x_{0} \in \mathbb{C}$, then

$$
\left\{\begin{array}{l}
x_{k+1}=(1-\alpha) x_{k}+\alpha T y_{k}, \\
y_{k}=(1-\beta) x_{k}+\beta T x_{k}, \quad k \in \mathbb{N},
\end{array}\right.
$$

where $\alpha, \beta \in(0,1]$.

(iii) Noor iteration [32]: given $x_{0} \in \mathbb{C}$, then

$$
\left\{\begin{array}{l}
x_{k+1}=(1-\alpha) T x_{k}+\alpha T y_{k}, \\
y_{k}=(1-\beta) T x_{k}+\beta T u_{k}, \\
u_{k}=(1-\xi) T x_{k}+\xi T x_{k}, \quad k \in \mathbb{N},
\end{array}\right.
$$

where $\alpha, \beta, \xi \in(0,1]$.

The Mann, Ishikawa and Noor iterations have been employed for generating Julia and Mandelbrot sets [23], superior Julia and Mandelbrot sets [19,20], relatively superior Julia and Mandelbrot sets [33-35], superfractals [36], generalized Julia sets [17] and polynomiographs [37-39]. Recently, Gdwaiec et al. [29] also considered the Mann and Ishikawa iterations with the Pickover algorithm for generating biomorphs.

In this paper, we study a more general and faster iteration method and employ it with the Pickover algorithm for generating biomorphs. In particular, we consider the following iteration: given $x_{0} \in \mathbb{C}$, then 


$$
\left\{\begin{array}{l}
x_{k+1}=T w_{k} \\
w_{k}=T\left((1-\xi) y_{k}+\xi T y_{k}\right), \\
y_{k}=T\left((1-\mu) z_{k}+\mu T z_{k}\right), \\
z_{k}=T\left((1-\alpha) x_{k}+\alpha T x_{k}\right), \quad k \in \mathbb{N},
\end{array}\right.
$$

where $\alpha, \mu, \xi \in(0,1]$. It is easy to see that the iteration process (4) is general than the Mann, Ishikawa and Noor iterations. Moreover, the convergence of (4) to a fixed point of a nonlinear mapping (when $\mathbb{C}$ is a real Banach space) was shown in [40]. Moreover, (4) has numerical advantages over Mann, Ishikawa Noor and many other iterations (see [40]).

\section{Escape Criterion Results}

The escape criterion plays a vital role in the generation and analysis of julia sets, Mandelbrot sets, and their generalizations. In this section, we describe some escape criterion for general polynomials of the form

$$
Q_{r}^{n}(x)=x^{n}+p x^{2}+m x+r
$$

where $n \geq 2, m, r \in \mathbb{C}, p \in\{0,1\}$.

It obviously contains quadratic, cubic and higher order polynomials. The presence of the term $p x^{2}$ makes it more general. The case when $p=1$ is just new and has never been studied in the literature in this context. Moreover, when $p=0$, we obtain the polynomial $Q_{r}^{n}(x)=x^{n}+m x+r$, which has been studied by some authors, for instance, Abbas et al. [24] and Nazeer et al. [41]. In addition, complex polynomials of the form (5) can be found in several problems arising from engineering such as digital signal processing. In particular, they are used in determining the pole-zero plots for signals and studying the structure and solutions of linear-time-variant [42].

Let $\mathbb{C}$ be a complex space, $Q_{r}^{n}: \mathbb{C} \rightarrow \mathbb{C}$ be a complex polynomial and $\left\{x_{k}\right\}$ be a sequence whose orbit around $x_{0}$ is generated by

$$
\left\{\begin{array}{l}
x_{k+1}=Q_{r}^{n}\left(w_{k}\right), \\
w_{k}=Q_{r}^{n}\left((1-\alpha) y_{k}+\alpha Q_{r}^{n} y_{k}\right), \\
y_{k}=Q_{r}^{n}\left((1-\eta) z_{k}+\eta Q_{r}^{n} z_{k}\right), \\
z_{k}=Q_{r}^{n}\left((1-\mu) x_{k}+\mu Q_{r}^{n} x_{k}\right), \quad k \in \mathbb{N},
\end{array}\right.
$$

where $\alpha, \eta, \mu \in(0,1]$.

\subsection{Escape Criterion for General Complex Polynomials}

We now give our escape criterion result for general complex polynomials.

Theorem 2. Let $Q_{r}^{n}(x)=x^{n}+p x^{2}+m x+r$, and suppose

$$
|x| \geq|r|>\max \left\{\frac{2(1+|m|)}{\mu\left(\left|r^{n-2}\right|+p\right)}, \frac{2(1+|m|)}{\eta\left(\left|r^{n-2}\right|+p\right)}, \frac{2(1+|m|)}{\alpha\left(\left|r^{n-2}\right|+p\right)}\right\},
$$

where $\alpha, \eta, \mu \in(0,1], r, m \in \mathbb{C}$ and $p \in\{0,1\}$. Define $\left\{x_{k}\right\}$ as in (6). Then, $\left|x_{k}\right| \rightarrow \infty$ as $k \rightarrow \infty$. 
Proof. Put $x_{0}=x, w_{0}=w, y_{0}=y, z_{0}=z$ and $u=(1-\mu) x+\mu Q_{r} x$. Then

$$
\begin{aligned}
|u| & =\left|(1-\mu) x+\mu Q_{r}^{n} x\right| \\
& =\left|(1-\mu) x+\mu\left(x^{n}+p x^{2}+m x+r\right)\right| \\
& \geq\left|(1-\mu) x+\mu\left(x^{n}+p x^{2}+m x\right)\right|-\mu|r| \\
& \geq\left|(1-\mu) x+\mu\left(x^{n}+p x^{2}+m x\right)\right|-\mu|x| \\
& \geq \mu\left|x^{n}+p x^{2}\right|-(1-\mu+\mu|m|)|x|-\mu|x| \\
& =\mu\left|x^{n}+p x^{2}\right|-(1+\mu|m|)|x| \\
& =|x|\left(\mu|x|\left(\left|x^{n-2}\right|+p\right)-(1+\mu|m|)\right) .
\end{aligned}
$$

Moreover, since $\mu \in(0,1]$, we get

$$
\begin{aligned}
|u| & \geq|x|\left(\mu|x|\left(\left|x^{n-2}\right|+p\right)-(1+|m|)\right) \\
& \geq|x|\left(\mu|x|\left(\left|r^{n-2}\right|+p\right)-(1+|m|)\right) \\
& =|x|(1+|m|)\left(\frac{\mu|x|\left(\left|r^{n-2}\right|+p\right)}{1+|m|}-1\right) .
\end{aligned}
$$

Thus

$$
\begin{aligned}
|u| & \geq \frac{|u|}{1+|m|} \\
& \geq|x|\left(\frac{\mu|x|\left(\left|r^{n-2}\right|+p\right)}{1+|m|}-1\right) .
\end{aligned}
$$

From the hypothesis of our theorem, we know that

$$
|x|>\frac{2(1+|m|)}{\mu\left(\left|r^{n-2}\right|+p\right)}
$$

which implies that

$$
\frac{\mu|x|\left(\left|r^{n-2}\right|+p\right)}{1+|m|}-1>1 .
$$

Hence

$$
|u|>|x| .
$$

\section{Consequently}

$$
\begin{aligned}
|z| & =\left|Q_{r}^{n}(u)\right| \\
& =\left|u^{n}+p u^{2}+m u+r\right| \\
& \geq\left|u^{n}+p u^{2}+m u\right|-|r| \\
& \geq\left|u^{n}+p u^{2}+m u\right|-|u| .
\end{aligned}
$$

Since $\mu \in(0,1]$, we have

$$
\begin{aligned}
|z| & \geq \mu\left|u^{n}+p u^{2}\right|-|m||u|-|u| \\
& =\mu\left|u^{2}\right|\left(\left|u^{n-2}\right|+p\right)-(1+|m|)|u| \\
& =|u|\left(\mu|u|\left(\left|u^{n-2}\right|+p\right)-(1+|m|)\right) \\
& >|u|\left(\mu|u|\left(r^{n-2} \mid+p\right)-(1+|m|)\right) .
\end{aligned}
$$


Since $|u|>|x|$, thus we have

$$
\begin{aligned}
|z| & \geq|x|\left(\mu|x|\left(\left|r^{n-2}\right|+p\right)-(1+|m|)\right) \\
& =|x|\left(\frac{\mu|x|\left(\left|r^{n-2}\right|+p\right)}{1+|m|}-1\right) .
\end{aligned}
$$

From (7), we get

$$
|z| \geq|x| .
$$

Following a similar argument as above, we have

$$
\begin{gathered}
|y|>|z| \text { and }|w|>|y|, \\
|w|>|y|>|z|>|x| .
\end{gathered}
$$

Furthermore, from (6), we have

$$
\begin{aligned}
\left|x_{1}\right| & =\left|Q_{r}^{n}(w)\right| \\
& =\left|w^{n}+p w^{2}+m w+r\right| \\
& \geq\left|w^{n}+p w^{2}+m w\right|-|r| \\
& \geq\left|w^{n}+p w^{2}+m w\right|-|w| \\
& \geq \alpha\left|w^{n}+p w^{2}\right|-|m||w|-|w| \\
& =\alpha\left|w^{n}+p w^{2}\right|-(1+|m|)|w| \\
& =|w|\left(\alpha|w|\left(\left|w^{n-2}\right|+p\right)-(1+|m|)\right) \\
& \geq|x|\left(\alpha|x|\left(\left|x^{n-2}\right|+p\right)-(1+|m|)\right)
\end{aligned}
$$

Hence

$$
\begin{aligned}
\left|x_{1}\right| & \geq|x|\left(\alpha|x|\left(\left|r^{n-2}\right|+p\right)-(1+|m|)\right) \\
& =|x|\left(\frac{\alpha|x|\left(\left|r^{n-2}\right|+p\right)}{1+|m|}-1\right)
\end{aligned}
$$

From the hypothesis of the theorem, we have

$$
|x|>\frac{2(1+|m|)}{\alpha\left(\left|r^{n-2}\right|+p\right)} .
$$

This implies that

$$
\frac{\alpha|x|\left(\left|r^{n-2}\right|+p\right)}{1+|m|}-1>1 .
$$

Hence, there exists a real number $\rho>0$ such that

$$
\frac{\alpha|x|\left(\left|r^{n-2}\right|+p\right)}{1+|m|}-1>1+\rho .
$$

Therefore

$$
\left|x_{1}\right|>(1+\rho)|x| .
$$

Hence by induction, we obtain

$$
\left|x_{k}\right|>(1+\rho)^{k}|x| .
$$


This means that $\left|x_{k}\right| \rightarrow \infty$ as $k \rightarrow \infty$. This completes the proof.

Note that the inclusion of the term $p x^{2}$ makes Theorem 2 way more interesting. We now draw some results for special values of $p$ from the above theorem.

When $p=1$, although the following result is a special case of our Theorem 2 above, yet it is new in itself.

Theorem 3. Let $Q_{r}^{n}(x)=x^{n}+p x^{2}+m x+r$, and suppose

$$
|x| \geq|r|>\max \left\{\frac{2(1+|m|)}{\mu\left(\left|r^{n-2}\right|+p\right)}, \frac{2(1+|m|)}{\eta\left(\left|r^{n-2}\right|+p\right)}, \frac{2(1+|m|)}{\alpha\left(\left|r^{n-2}\right|+p\right)}\right\},
$$

where $\alpha, \eta, \mu \in(0,1], r, m \in \mathbb{C}$ and $p \in\{0,1\}$. Define $\left\{x_{k}\right\}$ as in (6). Then $\left|x_{k}\right| \rightarrow \infty$ as $k \rightarrow \infty$.

When $p=0$, the following result generalizes Theorem 3 of Abbas et al. [24].

Theorem 4. Let $Q_{r}^{n}(x)=x^{n}+p x^{2}+m x+r$, and suppose

$$
|x| \geq|r|>\max \left\{\frac{2(1+|m|)}{\mu\left(\left|r^{n-2}\right|+p\right)}, \frac{2(1+|m|)}{\eta\left(\left|r^{n-2}\right|+p\right)}, \frac{2(1+|m|)}{\alpha\left(\left|r^{n-2}\right|+p\right)}\right\},
$$

where $\alpha, \eta, \mu \in(0,1], r, m \in \mathbb{C}$ and $p \in\{0,1\}$. Define $\left\{x_{k}\right\}$ as in (6). Then $\left|x_{k}\right| \rightarrow \infty$ as $k \rightarrow \infty$.

Now have a look at the following corollaries.

Corollary 1. Suppose $Q_{r}^{n}(x)=x^{n}+p x^{2}+m x+r$, and

$$
|x|>\max \left\{|r|, \frac{2(1+|m|)}{\mu\left(\left|r^{n-2}\right|+p\right)}, \frac{2(1+|m|)}{\eta\left(\left|r^{n-2}\right|+p\right)}, \frac{2(1+|m|)}{\alpha\left(\left|r^{n-2}\right|+p\right)}\right\},
$$

where $\alpha, \eta, \mu \in(0,1], r, m \in \mathbb{C}$ and $p \in\{0,1\}$. Define $\left\{x_{k}\right\}$ as in (6). Then, $\left|x_{k}\right| \rightarrow \infty$ as $k \rightarrow \infty$.

Corollary 2. If for any $k \geq 0$, we have that

$$
\left|x_{k}\right| \geq|r|>\max \left\{\frac{2(1+|m|)}{\mu\left(\left|r^{n-2}\right|+p\right)}, \frac{2(1+|m|)}{\eta\left(\left|r^{n-2}\right|+p\right)}, \frac{2(1+|m|)}{\alpha\left(\left|r^{n-2}\right|+p\right)}\right\},
$$

where $\alpha, \eta, \mu \in(0,1], r, m \in \mathbb{C}$ and $p \in\{0,1\}$. Then $\left|x_{k+1}\right|>(1+\rho)^{k}\left|x_{k}\right|$ for some $\rho>0$ so that $\left|x_{k}\right| \rightarrow \infty$ as $k \rightarrow \infty$.

Next, we have a look at escape criterion for cubic and quadratic polynomials.

\subsection{Escape Criterion for Cubic Complex Polynomials}

Theorem 5. Let $Q_{r}^{3}(x)=x^{3}+p x^{2}+m x+r$, and suppose

$$
|x| \geq|r|>\max \left\{\frac{2(1+|m|)}{\mu(|r|+p)}, \frac{2(1+|m|)}{\eta(|r|+p)}, \frac{2(1+|m|)}{\alpha(|r|+p)}\right\},
$$

where $\alpha, \eta, \mu \in(0,1], r, m \in \mathbb{C}$ and $p \in\{0,1\}$. Define $\left\{x_{k}\right\}$ as in (6). Then $\left|x_{k}\right| \rightarrow \infty$ as $k \rightarrow \infty$.

Remark 1. The above theorem is a special case of Theorem 2 when $n=3$.

The following corollaries can be obtained from Theorem 5 
Corollary 3. Suppose $Q_{r}^{3}(x)=x^{3}+p x^{2}+m x+r$, and

$$
|x|>\max \left\{|r|, \frac{2(1+|m|)}{\mu(|r|+p)}, \frac{2(1+|m|)}{\eta(|r|+p)}, \frac{2(1+|m|)}{\alpha(|r|+p)}\right\},
$$

where $\alpha, \eta, \mu \in(0,1], r, m \in \mathbb{C}$ and $p \in\{0,1\}$. Define $\left\{x_{k}\right\}$ as in (6). Then $\left|x_{k}\right| \rightarrow \infty$ as $k \rightarrow \infty$.

Corollary 4. If for any $k \geq 0$, we have that

$$
\left|x_{k}\right| \geq|r|>\max \left\{\frac{2(1+|m|)}{\mu(|r|+p)}, \frac{2(1+|m|)}{\eta(|r|+p)}, \frac{2(1+|m|)}{\alpha(|r|+p)}\right\},
$$

where $\alpha, \eta, \mu \in(0,1], r, m \in \mathbb{C}$ and $p \in\{0,1\}$. Then $\left|x_{k+1}\right|>(1+\rho)^{k}\left|x_{k}\right|$ for some $\rho>0$ so that $\left|x_{k}\right| \rightarrow \infty$ as $k \rightarrow \infty$.

\subsection{Escape Criterion for Quadratic Complex Polynomials}

The following theorem is a special case of Theorem 2 when $n=2$.

Theorem 6. Let $Q_{r}^{2}(x)=(1+p) x^{2}+m x+r$, and suppose

$$
|x| \geq|r|>\max \left\{\frac{2(1+|m|)}{\mu(1+p)}, \frac{2(1+|m|)}{\eta(1+p)}, \frac{2(1+|m|)}{\alpha(1+p)}\right\},
$$

where $\alpha, \eta, \mu \in(0,1], r, m \in \mathbb{C}$ and $p \in\{0,1\}$. Define $\left\{x_{k}\right\}$ as in (6). Then, $\left|x_{k}\right| \rightarrow \infty$ as $k \rightarrow \infty$.

The following are refinements of this theorem.

Corollary 5. Suppose $Q_{r}^{2}(x)=(1+p) x^{2}+m x+r$, and let

$$
|x|>\max \left\{|r|, \frac{2(1+|m|)}{\mu(1+p)}, \frac{2(1+|m|)}{\eta(1+p)}, \frac{2(1+|m|)}{\alpha(1+p)}\right\},
$$

where $\alpha, \eta, \mu \in(0,1], r, m \in \mathbb{C}$ and $p \in\{0,1\}$. Define $\left\{x_{k}\right\}$ as in (6). Then, $\left|x_{k}\right| \rightarrow \infty$ as $k \rightarrow \infty$.

Corollary 6. Suppose $Q_{r}^{2}(x)=(1+p) x^{2}+m x+r$. If for any $k \geq 0$, we have

$$
\left|x_{k}\right| \geq|r|>\max \left\{\frac{2(1+|m|)}{\mu(1+p)}, \frac{2(1+|m|)}{\eta(1+p)}, \frac{2(1+|m|)}{\alpha(1+p)}\right\},
$$

where $\alpha, \eta, \mu \in(0,1], r, m \in \mathbb{C}$ and $p \in\{0,1\}$. Then $\left|x_{k+1}\right|>(1+\rho)^{k}\left|x_{k}\right|$ for some $\rho>0$ so that $\left|x_{k}\right| \rightarrow \infty$ as $k \rightarrow \infty$.

Note that Corollary 6 provides a condition for computing the filled Julia set for the quadratic polynomials. Indeed, for any point satisfying $|x| \geq|r|$, we find out the orbit of $x$. If for any $k,\left|x_{k}\right|$ lies outside the circle of radius $\max \left\{\frac{2(1+|m|)}{\mu(1+p)}, \frac{2(1+|m|)}{\eta(1+p)}, \frac{2(1+|m|)}{\alpha(1+p)}\right\}$, then, we say that the orbit escapes to infinity, which means that $x$ is not in the filled Julia set. Otherwise, if $\left|x_{k}\right|$ never exceeds this bound, then $x$ is by definition in the Julia set.

\section{Biomorphs Generation}

In this section, we present some biomorphs for quadratic, cubic and higher degree polynomials. We investigated the change of parameters on the shape and variation of colors on the biomorphs. New sets of biomorphs were obtained with interesting distinct features. The biomorphs are generated using Lenovo PC with the following specification: Intel(R)core i7-600, CPU 2.48 GHz, 
RAM 8.0 GB, MATLAB version 9.5 (R2019b). The pseudo-code for generating the biomorphs is presented in Algorithm 1.

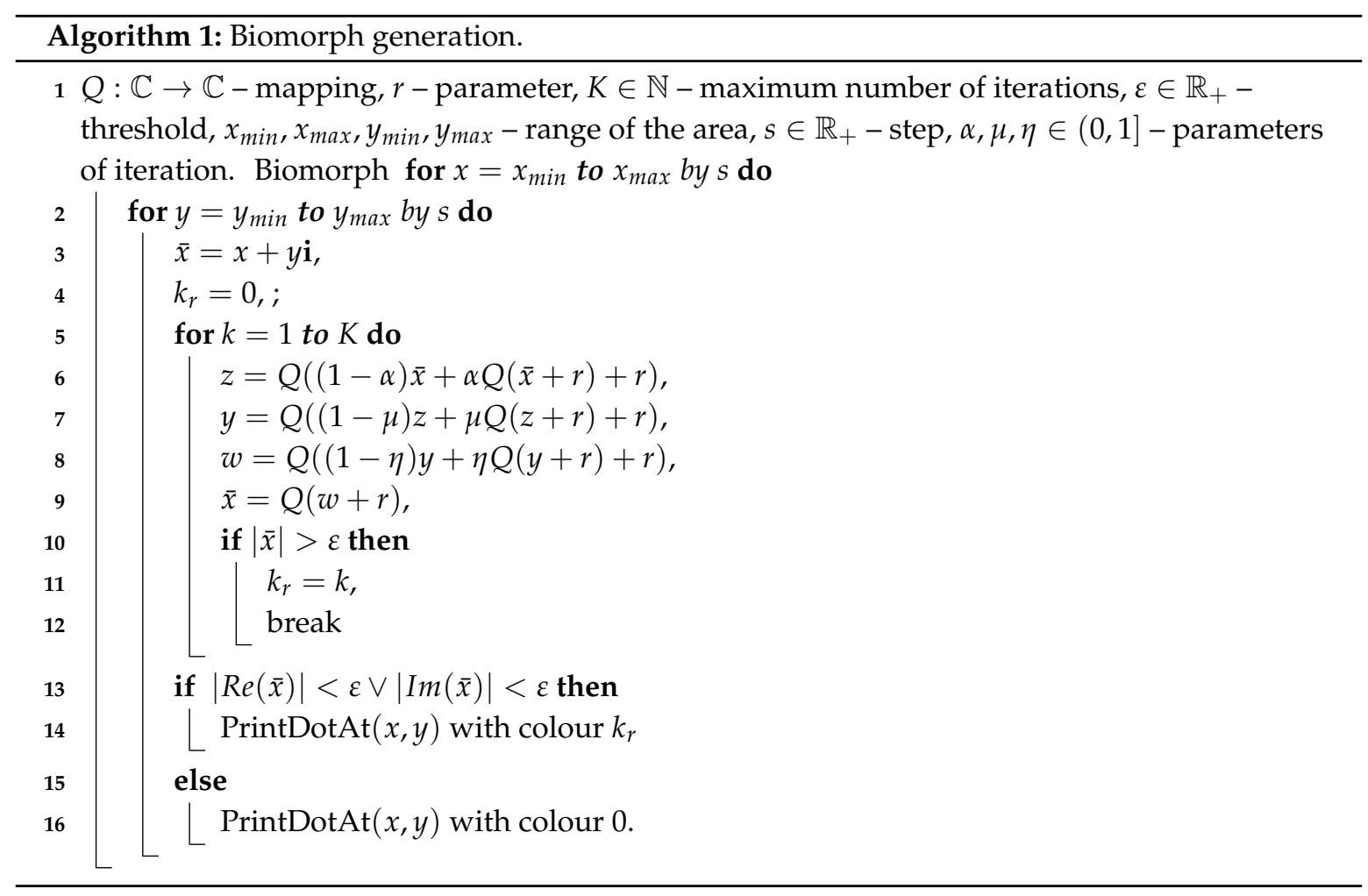

Now, we present the biomorphs generated by using Algorithm 1. For all our examples, we choose $A=\left[x_{\min }, x_{\max }\right] \times\left[y_{\min }, y_{\max }\right]=[-2,2] \times[-2,2], s=600, \varepsilon=10, K=5$.

Example 1. We consider the polynomial $Q(x)=x^{2}+(-0.5+0.7 \mathbf{i}) x+(-0.1+0.18 \mathbf{i})$. We vary the values of $r$ and parameters $\alpha, \mu, \eta$ as follows:
(a) $r=0.64, \mu=0.31, \eta=0.631, \alpha=0.513$;
(b) $\quad r=0.32 \mu=0.15, \eta=0.289, \alpha=0.720$;
(c) $r=2.5 \mathbf{i}, \mu=0.05, \eta=0.731, \alpha=0.910$;
(d) $\quad r=-5 \mathbf{i}, \mu=0.790, \eta=0.487, \alpha=0.834$.

Figures 1-4 present the obtained biomorphs. From the images, we see that the change in the parameters alters the colours and shapes of the biomorphs. Moreover, we can observed that the use of complex value of $r$ adds swirls and twists to the obtained patterns. This makes the images look more dynamics and vivid.

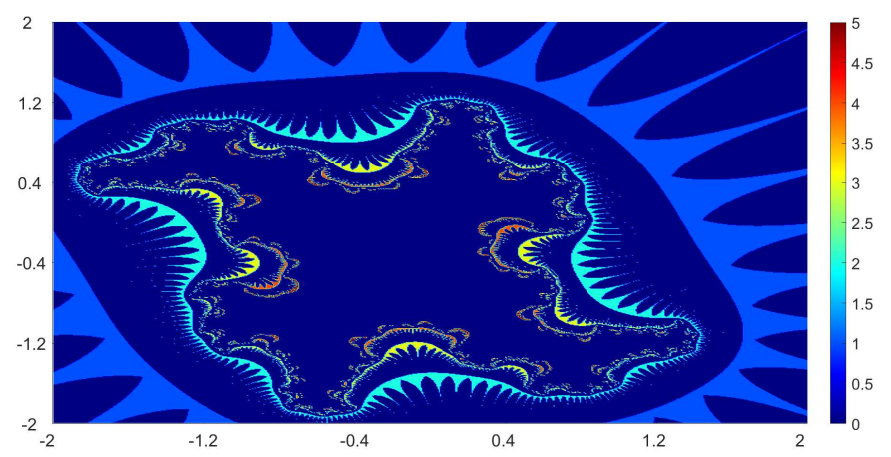

Figure 1. Example 1(a). 


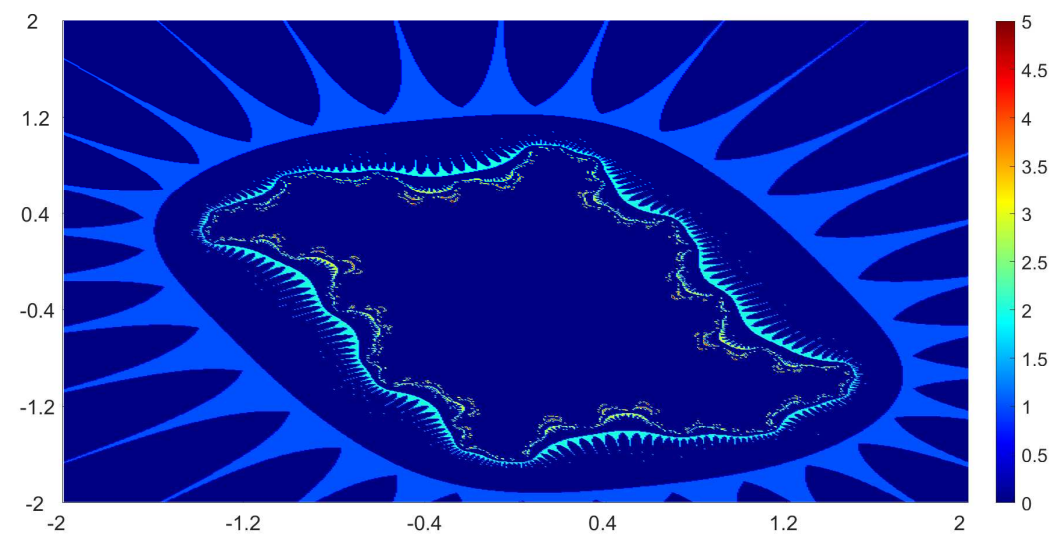

Figure 2. Example 1(b).

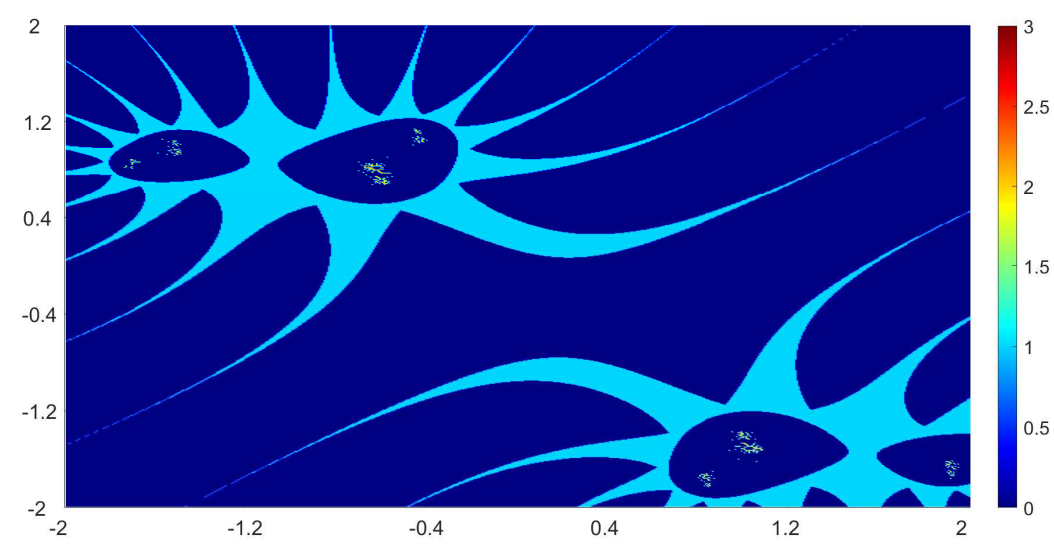

Figure 3. Example 1(c).

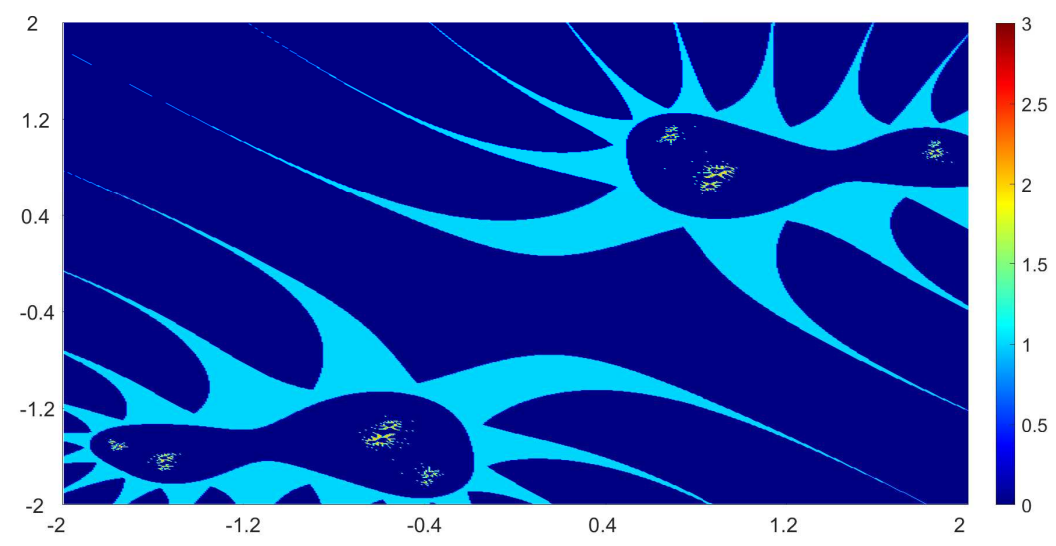

Figure 4. Example 1(d).

Example 2. In this example, we consider the quadratic polynomial $Q(x)=2 x^{2}-3 x$ and choose the parameter $r=r_{n}$ using the following switching technique [29], i.e.,

$$
\left\{\begin{array}{l}
r_{0}=t_{1}, \\
r_{2 n-1}=\frac{1}{t_{1}^{2 n-1}}-r_{2 n-2}, \quad n \geq 1 \\
r_{2 n}=\frac{1}{t_{2}^{2 n}}-r_{2 n-1}, \quad n \geq 1,
\end{array}\right.
$$


where $t_{1}, t_{2}$ are non-zero complex variables. We fixed the parameters $\mu=0.591, \eta=0.327, \alpha=0.614$ and vary the values of $t_{1}$ and $t_{2}$ as follows:
(a) $t_{1}=0.88, t_{2}=1.25$;
(b) $t_{1}=1.87, t_{2}=3.19$;
(c) $t_{1}=2+0.89 \mathbf{i}, t_{2}=-2+0.77 \mathbf{i}$;
(d) $t_{1}=0.89 \mathbf{i}, t_{2}=0.61 \mathbf{i}$.

The generated biomorphs are shown in Figures 5-8. In the switching technique, it is seen that a small change in the values of $t_{1}$ and $t_{2}$ caused significant changes in the shapes, colours and dynamics of the biomorphs.

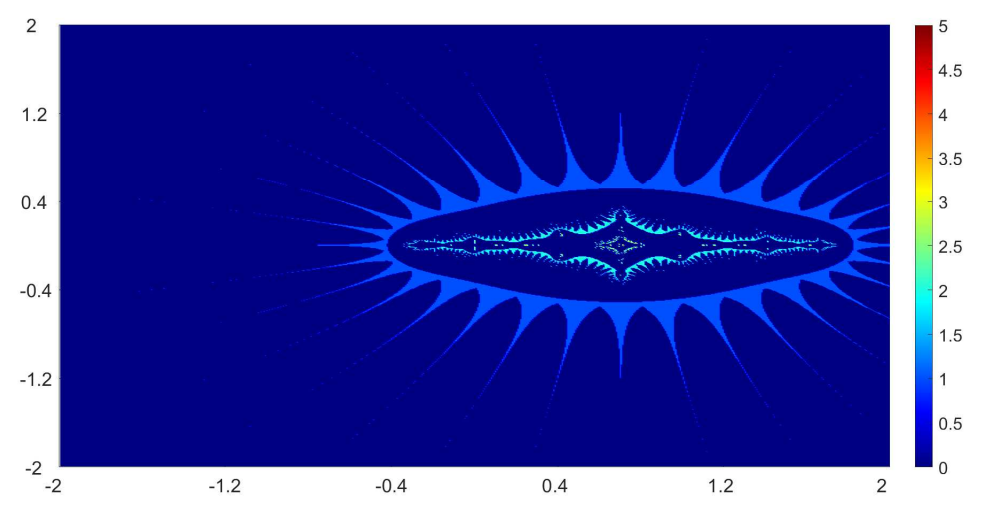

Figure 5. Example 2(a).

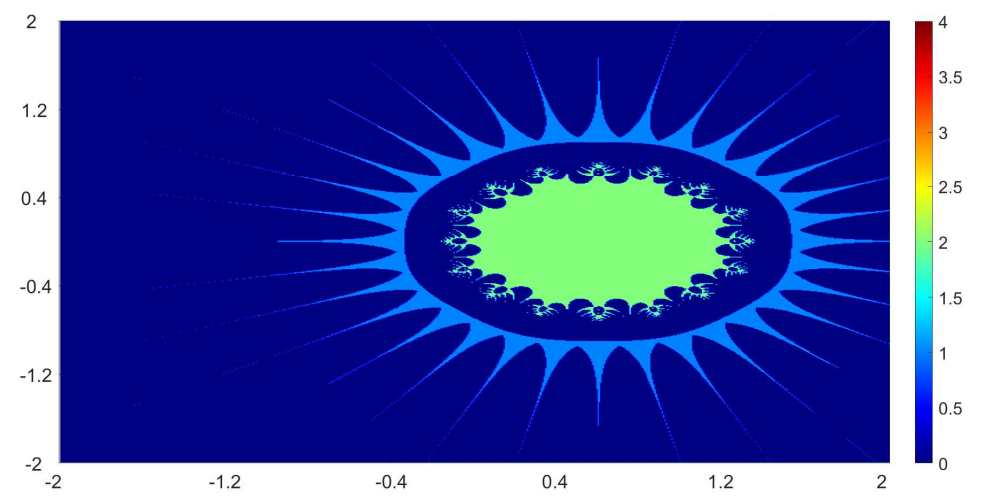

Figure 6. Example 2(b).

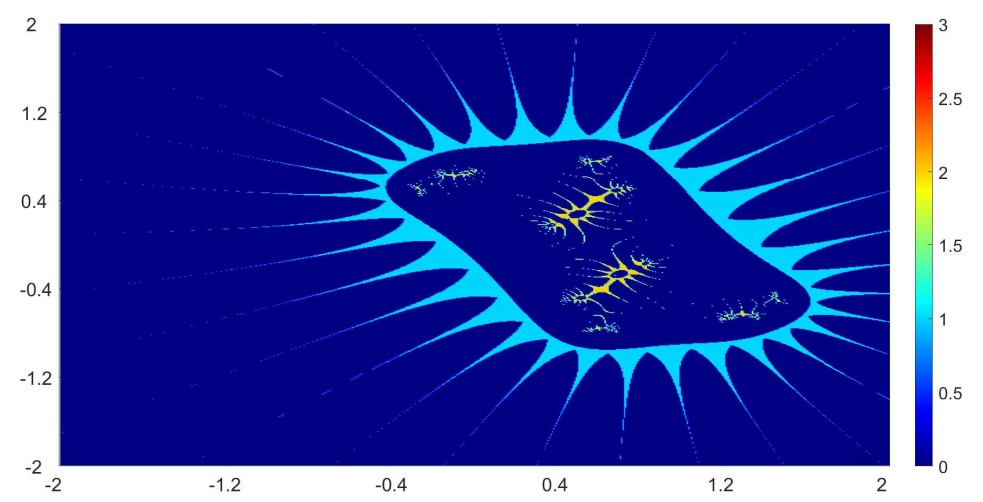

Figure 7. Example 2(c). 


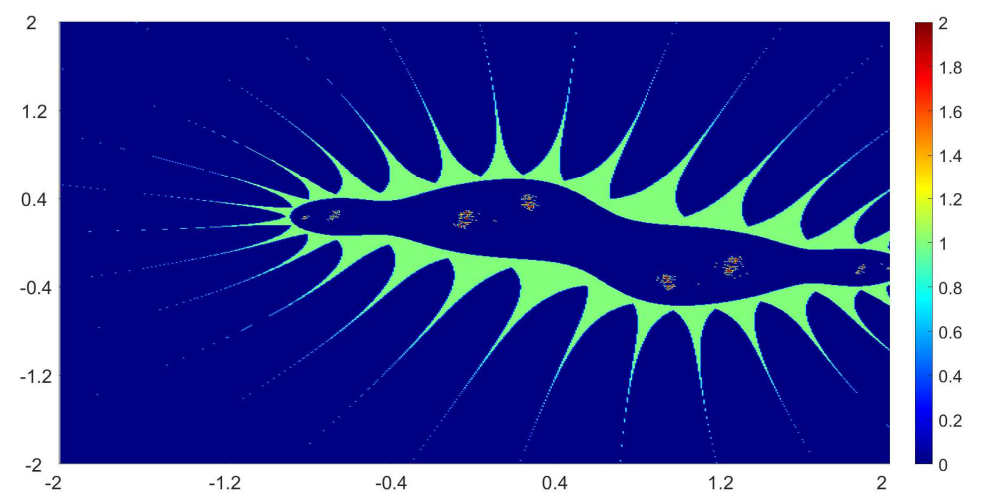

Figure 8. Example 2(d).

Example 3. We consider the cubic polynomial $Q(x)=x^{3}+x^{2}-3 x+1$ and choose $r_{n}$ using the switch technique as in the previous example. We vary the values of $t_{1}, t_{2}, \mu, \eta$ and $\alpha$ as follows:
(a) $t_{1}=0.89 \mathbf{i}, t_{2}=0.68 \mathbf{i}, \mu=0.5, \eta=0.09, \alpha=0.25$;
(b) $t_{1}=0.39, t_{2}=3.5, \mu=0.15, \eta=0.49, \alpha=0.325$;
(c) $t_{1}=-0.39, t_{2}=-2, \mu=0.35, \eta=0.15, \alpha=0.625$;
(d) $t_{1}=1.68 \mathbf{i}, t_{2}=-2.89, \mu=0.75, \eta=0.69, \alpha=0.425$.

Figures 9-12 show the generated biomorphs. It is seen that a small change in the value of the parameters caused significant change in the shapes and dynamics of the biomorphs.

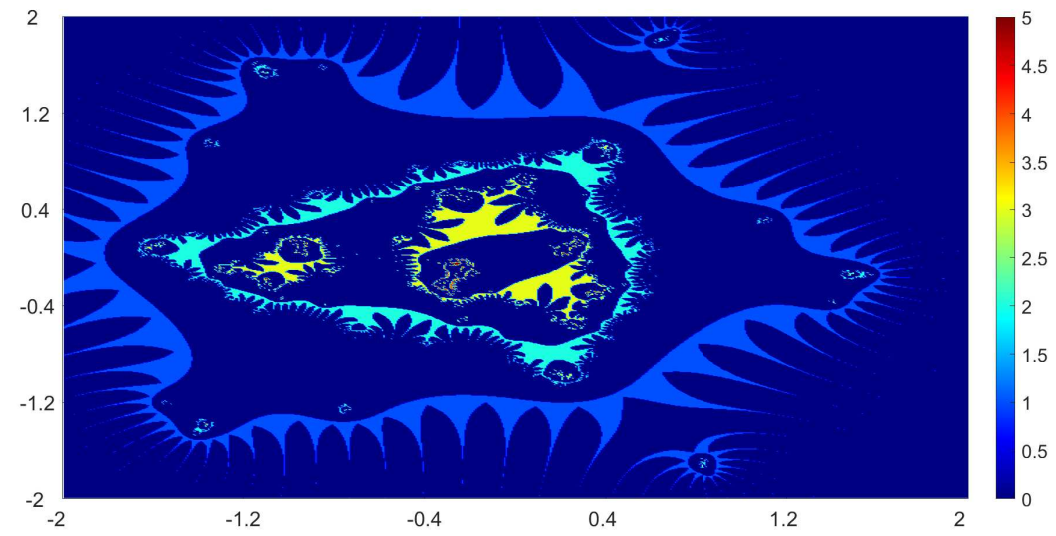

Figure 9. Example 3(a).

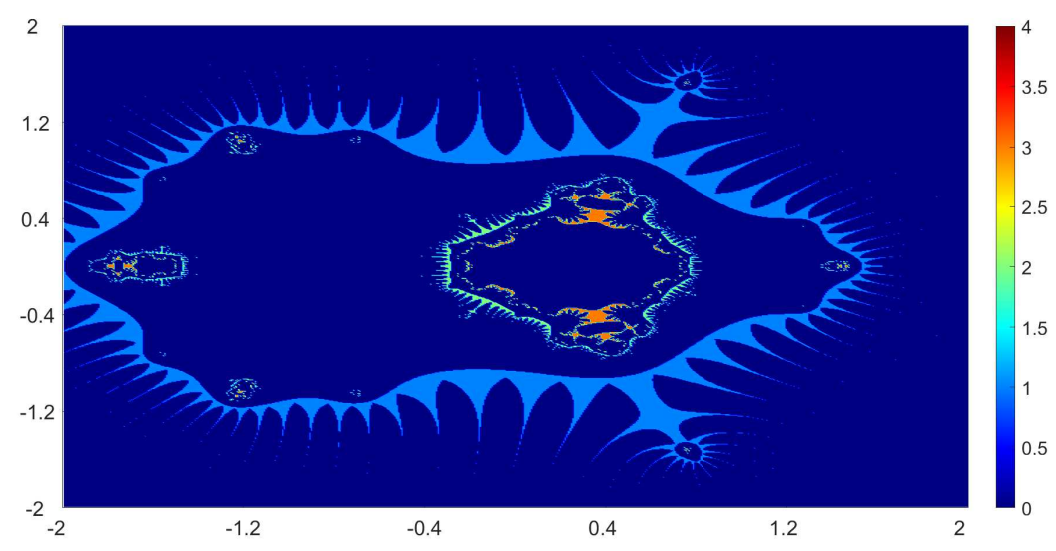

Figure 10. Example 3(b). 


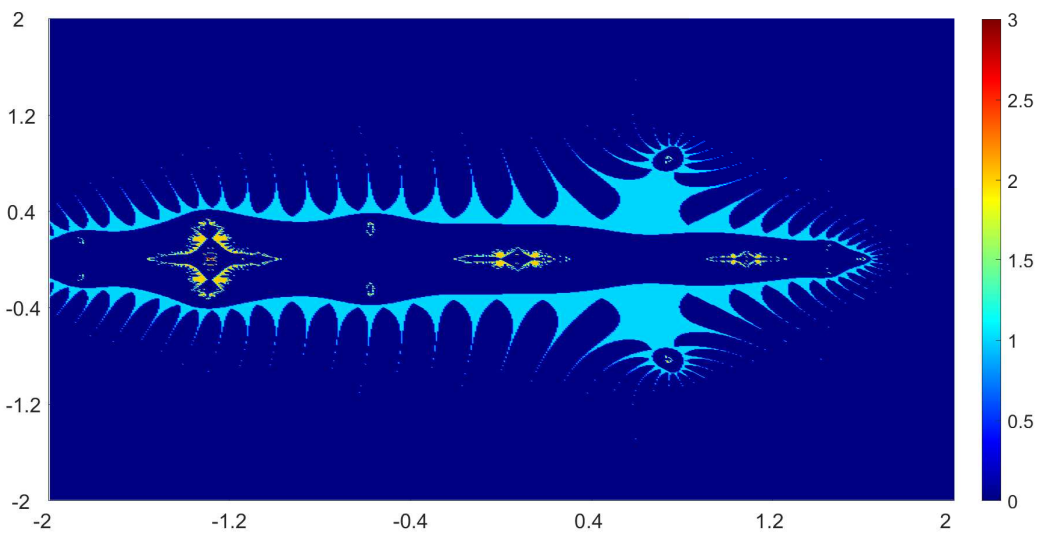

Figure 11. Example 3(c).

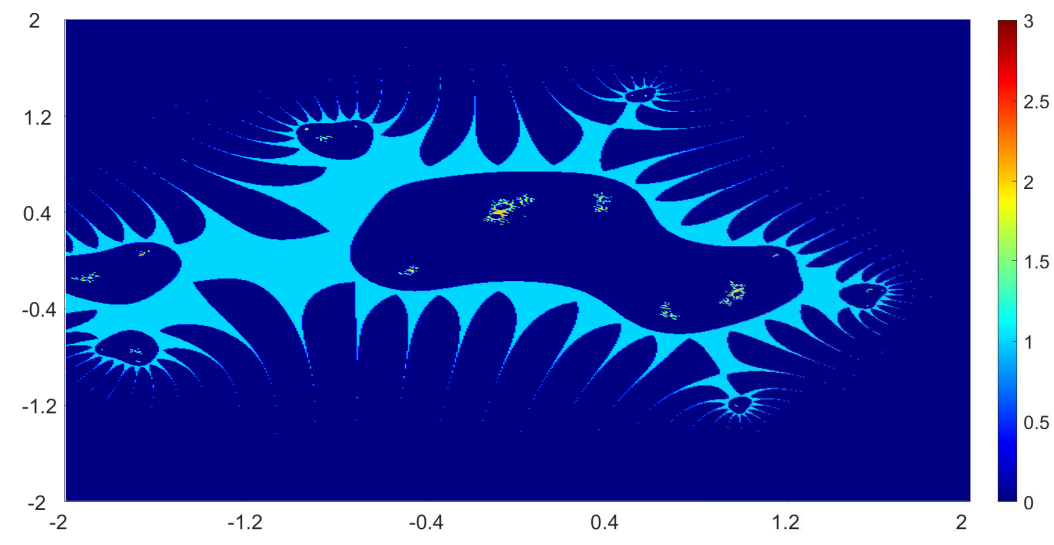

Figure 12. Example 3(d).

Example 4. We consider the polynomial $Q(x)=x^{6}+x^{2}+1$ and vary the values of $r, \mu, \eta, \alpha$ as follows:
(a) $r=0.68, \mu=0.275, \eta=0.169, \alpha=0.343$;
(b) $\quad r=0.37, \mu=0.0569, \eta=0.0175, \alpha=0.0521$;
(c) $\quad r=0.037, \mu=0.175, \eta=0.0331, \alpha=0.0221$
(d) $\quad r=0.0037, \mu=0.0175, \eta=0.00331, \alpha=0.00221$.

The obtained biomorphs are shown in Figures 13-16. We see that the change in the parameters has great impact on the shape of the obtained biomorphs.

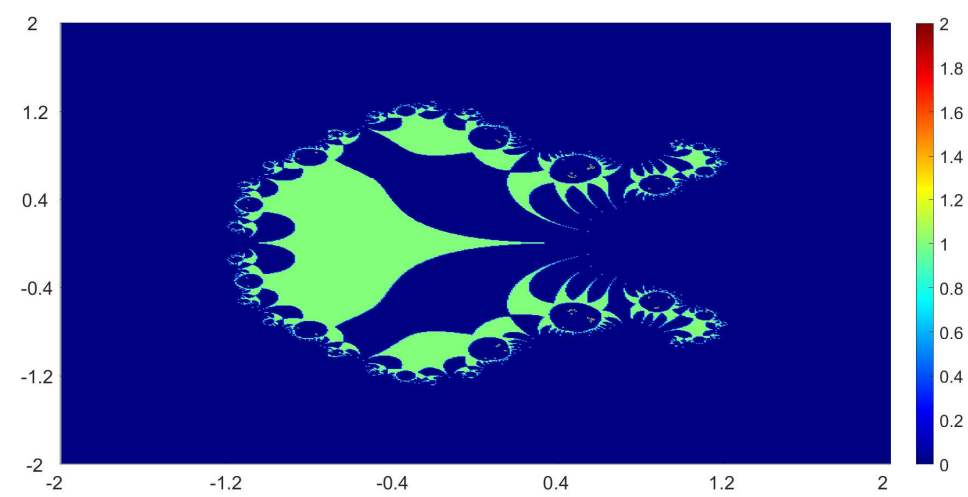

Figure 13. Example 4(a). 


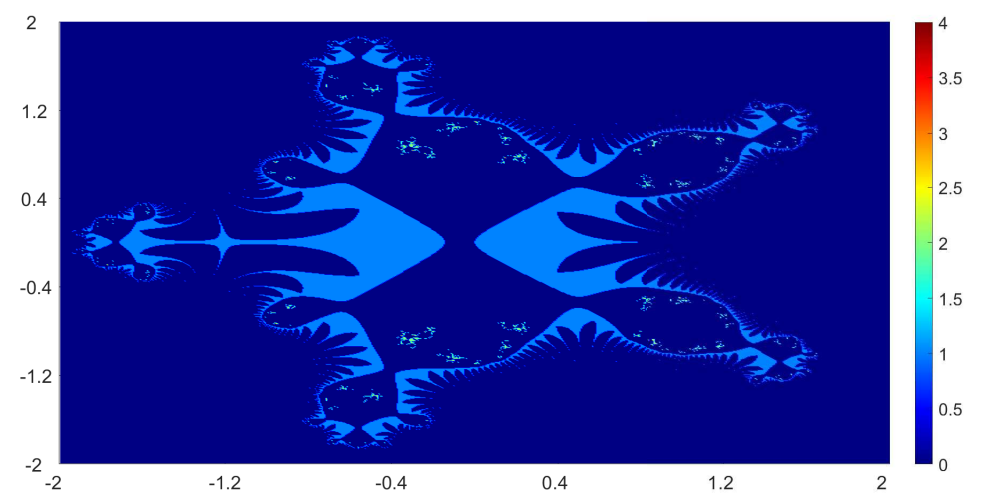

Figure 14. Example 4(b).

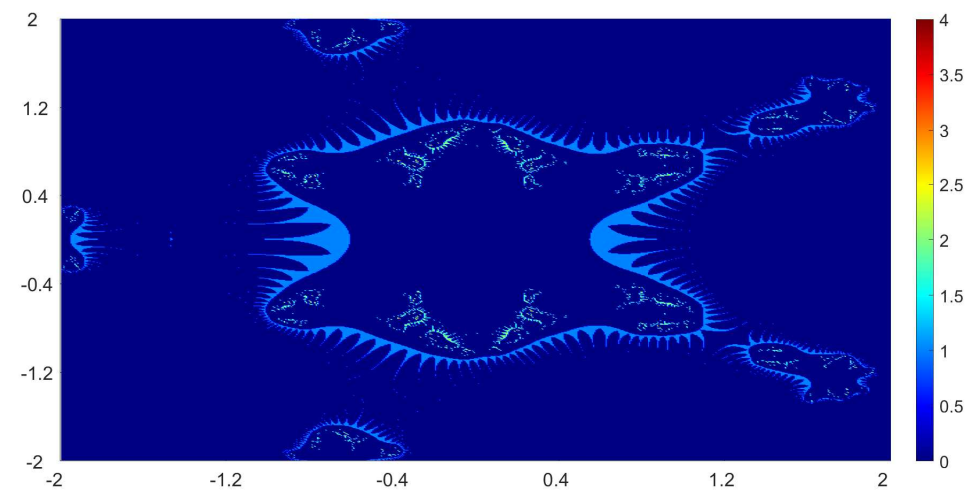

Figure 15. Example 4(c).

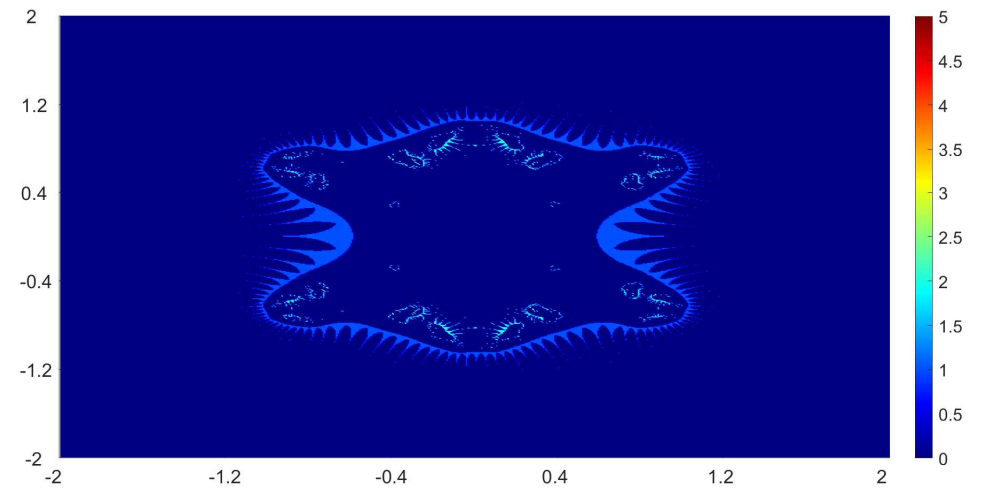

Figure 16. Example 4(d).

Example 5. Finally, in this last example, we consider a complex hyper-function $Q(x)=x^{x}$ with different values of $r$ as follows:
(a) $r=0.15$
(b) $r=0.35$;
(c) $r=0.45$;
(d) $r=0.55$.

We also take $\alpha=0.25, \mu=0.64, \eta=0.73$. The obtained graphics are shown in Figures $17-20$. We note that the obtained biomorphs do not really have organismic structure, however, the obtained graphics are very fascinating from an artistic point of view. These can be of interest to someone working in automatic creation of nice looking 
objects and general artworks. Moreover, the change in the value of $r$ produced different graphics with distinct colours, shapes and dynamics.

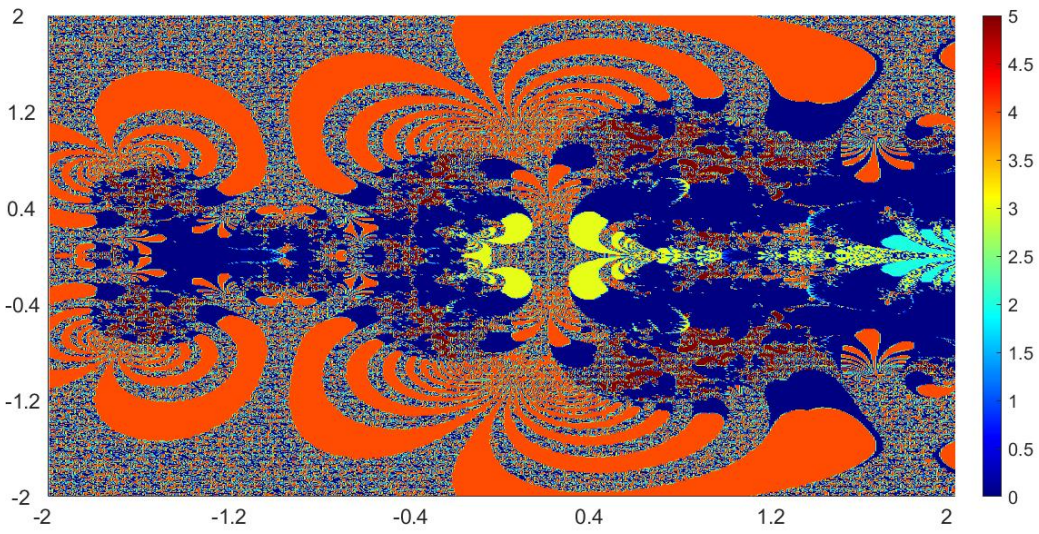

Figure 17. Example 5(a).

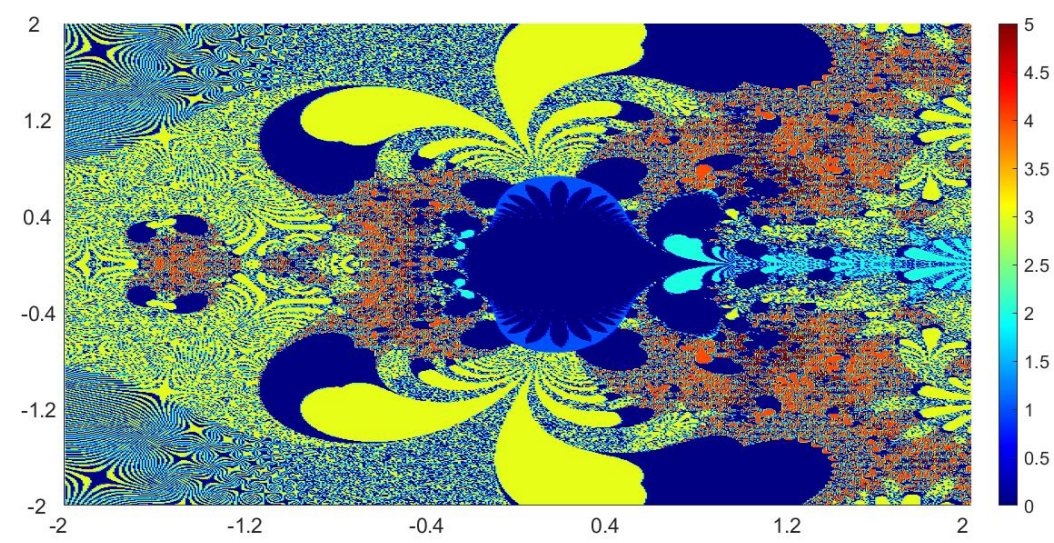

Figure 18. Example 5(b).

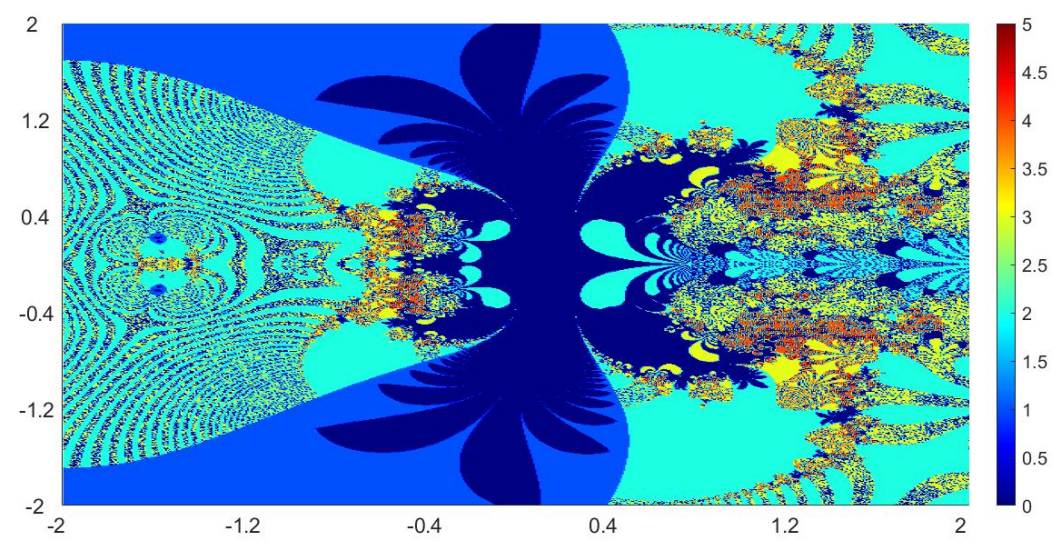

Figure 19. Example 5(c). 


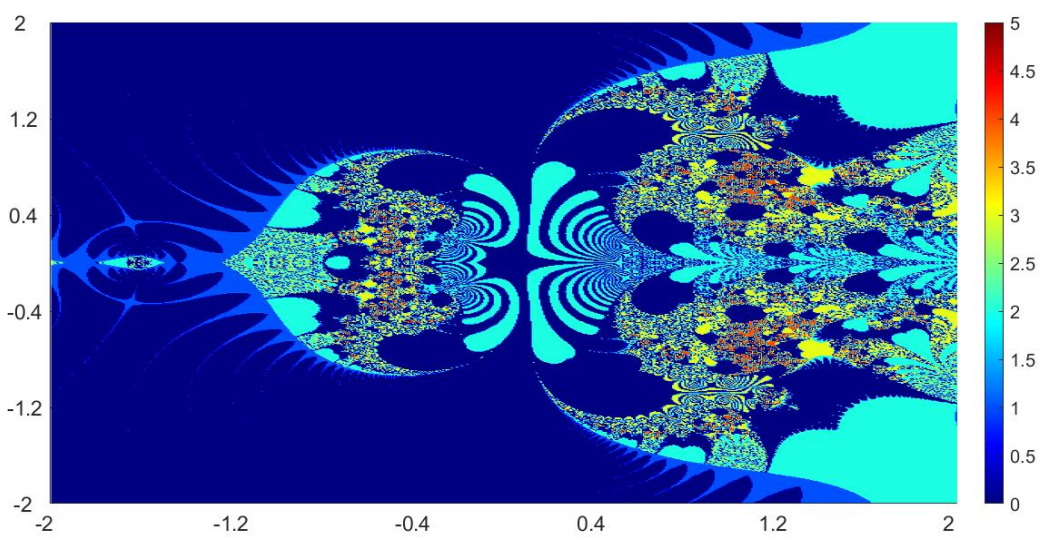

Figure 20. Example 5(d).

\section{Conclusions}

In this paper, a new general iteration was used to study the behaviour of biomorphs with complex polynomials. The escape criterion for quadratic, cubic and higher degree polynomials for the general iteration were presented. Some new sets of biomorphs were also generated. It was observed that the variation of parameters caused changes in the dynamics, colours and shapes of biomorphs in most cases. The obtained biomorphs are interestingly different in comparison to those obtained by Pickover (using standard Picard iteration) [25] and Gdawiec (using Mann and Ishikawa iterations) [29].

In our future research, we would like to extend the works of Negi et al. [34] and Rani et al. [35] on the noise in superior Mandelbrot set and superior Julia sets respectively to modified biomorphs introduced in this paper. Moreover, it is interesting to develop automatic biomorphs searching methods like those proposed in Ashlook et al. for Julia set $[43,44]$. Furthermore, we will like to study other category of fractals types of complex fractals and inversion fractals with respect to the generation of biomorphs.

Finally, we note that the work in this paper can be developed by using other non-standard iterations (see [37,45]) known in fixed point theory for generating biomorphs.

Author Contributions: Conceptualization, L.O.J. and S.H.K.; methodology, S.H.K.; software, L.O.J.; validation, L.O.J. and S.H.K.; formal analysis, L.O.J.; investigation, L.O.J. and S.H.K.; writing-original draft preparation, L.O.J.; writing-review and editing, S.H.K.; visualization, L.O.J.; supervision, S.H.K.; project administration, S.H.K.; funding acquisition, L.O.J.; Correspondence, S.H.K. All authors have read and agreed to the published version of the manuscript.

Funding: This research is supported by the Mathematics and Applied Mathematics Research fund, Sefako Makgatho Health Sciences University, Ga-Rankuwa, Pretoria.

Acknowledgments: The authors acknowledge the financial support of Sefako Makgatho Health Sciences University toward the APC payment. L.O. Jolaoso, thanks Department of Mathematics and Applied Mathematics at the Sefako Makgatho Health Sciences University for making their facilities available for the research. L.O. Jolaoso is supported by a Postdoctoral research grant from the Sefako Makgatho Health Sciences University, South Africa.

Conflicts of Interest: The authors declare that there is no conflict of interest.

\section{References}

1. Grigson, G. The Arts Today; Bodley Head: London, UK, 1935; pp. 71-109.

2. Britannica. Available online: https:/ / www.britannica.com/art/biomorphic-art (accessed on 26 November 2020).

3. Rafati, V.; Sahba, F. “Bahai temples”. In Encyclopædia Iranica; Springer: New York, NY, USA, 1989.

4. Zerbst, R. Antoni Gaudi-A Life Devoted to Architecture. Trans. from German by Doris Jones and Jeremy Gaines; Taschen: Hamburg, Germany, 1988; p. 30, ISBN 3-8228-0074-0.

5. Eidelberg, M.; Carmel, K. Design 1935-1965: What modern was: Selections from the Liliane and David M. In Stewart Collection, Montreal: Musée des arts Décoratifs de Montréal; Abrams: New York, NY, USA, 1991; p. 90. 
6. Pina, L. Classic Herman Miller; Schiffer Publishing: Atglen, PA, USA, 1998; ISBN 0-7643-0471-2.

7. Negi, A.; Rani, M.; Mahanti, P.K. Computer simulation of the behavior of Julia sets using switching processes. Chaos Solitons Fractals 2008, 37, 1187-1192. [CrossRef]

8. Andreadis, I.; Karakasidis, T.E. On a topological closeness of perturbed Julia sets. Appl. Math. Comput. 2010, 217, 2883-2890. [CrossRef]

9. Peitgen, H.O.; Jurgens, H.; Saupe, D. Chaos and Fractals; Springer: New York, NY, USA, 1992.

10. Rani, M.; Negi, A. New Julia sets for complex Carotid-Kundalini function. Chaos Solitons Fractals 2008, 36, 226-236. [CrossRef]

11. Lei, T. Similarity between the Mandelbrot sets and Julia sets. Commun. Math. Phys. 1990, 134, 587-617. [CrossRef]

12. Mandelbrot, B.B. The Fractal Geometry of Nature; W. H. Freeman: San Francisco, CA, USA, 1982.

13. Crilly, A.J.; Earnshaw, R.A.; Jones, H. Fractals and Chaos; Springer: New York, NY, USA, 1991.

14. Devaney, R.L. A First Course in Chaotic Dynamical Systems: Theory and Experiment; Addison-Wesley: Boston, MA, USA, 1992.

15. Branner, B.; Hubbard, J.H. The iteration of cubic polynomials Part I: The global topology of parameter space. Acta Math. 1988, 160, 143-206. [CrossRef]

16. Branner, B.; Hubbard, J.H. The iteration of cubic polynomials Part II: Patterns and parapatterns. Acta Math. 1992, 169, 229-325. [CrossRef]

17. Frame, M.; Robertson, J. A generalized Mandelbrot set and the role of critical points. Comput. Graph. 1992, 16, 35-40. [CrossRef]

18. Geum, Y.H.; Hare, K.G. Groebner basis, resultants and the generalized Mandelbrot set. Chaos Solitons Fractals 2009, 42, 1016-1023. [CrossRef]

19. Rani, M.; Kumar, V. Superior Julia set. Res. Math. Educ. 2004, 8, 261-277.

20. Rani, M.; Kumar, V. Superior Mandelbrot set. Res Math Educ. 2004, 8, 279-291.

21. Chauhan, Y.S.; Rana, R.; Negi, A. New Julia sets of Ishikawa iterates. Int. J. Comput. Appl. 2010, 7, 34-42. [CrossRef]

22. Chauhan, Y.S.; Rana, R.; Negi, A. Complex dynamics of Ishikawa iterates for non integer values. Int. J. Comput. Appl. 2010, 9, 9-16. [CrossRef]

23. Rani, A.; Chugh, R. Julia sets and Mandelbrot sets in Noor orbit. Appl. Math. Comput. 2014, 228, 615-631.

24. Abbas, M.; Iqbal, H.; Sen, M.D.L. Generation of Julia and Madelbrot sets via fixed points. Symmetry 2020, 12, 86, doi:10.3390/sym12010086. [CrossRef]

25. Pickover, C.A. Biomorphs: Computer Displays of Biological Forms Generated from Mathematical Feedback Loops. Comput. Graph. Forum 1986, 5, 313-316. [CrossRef]

26. Levin, M. Morphogenetic Fields in Embryogenesis, Regeneration, and Cancer: Non-local Control of Complex Patterning. BioSystems 2012, 109, 243-261. [CrossRef]

27. Leys, J. Biomorphic Art: An Artist's Statement. Comput. Graph. 2002, 26, 977-979. [CrossRef]

28. Mojica, N.S.; Navarro, J.; Marijuán, P.C.; Lahoz-Beltra, R. Cellular "bauplants": Evolving Unicellular Forms by Means of Julia Sets and Pickover Biomorphs. BioSystems 2009, 98, 19-30. [CrossRef]

29. Gdawiec, K.; Kotarski, W.; Lisowska, A. Biomorphs via modified iterations. J. Nonlinear Sci. Appl. 2016, 9 , 2305-2315. [CrossRef]

30. Mann, W.R. Mean Value Methods in Iteration. Proc. Amer. Math. Soc. 1953, 4, 506-510. [CrossRef]

31. Ishikawa, S. Fixed Points by a New Iteration Method. Proc. Amer. Math. Soc. 1974, 44, 147-150. [CrossRef]

32. Noor, M.A. New approximation schemes for general variational inequalities. J. Math. Anal. Appl. 2000, 251, 217-229. [CrossRef]

33. Agarwal, R.; Agarwal, V. Dynamic noise perturbed generalized superior Mandelbrot sets. Nonlinear Dyn. 2011, 67, 1883-1891. [CrossRef]

34. Negi, A.; Rani, M. A new approach to dynamic noise on superior Mandelbrot set. Chaos Solitons Fractals 2008, 36, 1089-1096. [CrossRef]

35. Rani, M.; Agarwal, R. Effect of stochastic noise on superior Julia sets. J. Math. Imaging Vis. 2010, 36, 63-68. [CrossRef]

36. Singh, S.L.; Jain, S.; Mishra, S.N. A New Approach to Superfractals. Chaos Solitons Fractals 2009, 42, 3110-3120. [CrossRef] 
37. Gdawiec, K.; Kotarski, W.; Lisowski, A. Polynomiography based on the nonstandard Newton-like root finding methods. Abstr. Appl. Anal. 2015, 2015, 19. [CrossRef]

38. Gdawiec, K.; Shahid, A.A.; Nazeer, W. Higher order methods of the Basic Family of Iterations via S-iteration with s-convexity. Mediterr. J. Math. 2020, 17, 43. 10.10007/s00009-020-1491-y. [CrossRef]

39. Kotarski, W.; Gdawiec, K.; Lisowska, A. Polynomiography via Ishikawa and Mann iterations. Lect. Notes Comput. Sci. 2012, 7431, 305-313. [CrossRef]

40. Garodia, C.; Uddin, I.; Khan, S.H. Approximating common fixed point by a new faster iteration. accepted.

41. Nazeer, W.; Kang, S.M.; Tanveer, M.; Shahid, A.A. Fixed point results in the generation of Julia and Mandelbrot sets. J. Ineq. Appl. 2015, 2015, 298. [CrossRef]

42. Proakis, .J.G.; Manolakis, D.G. Digital Signal Processing: Principles, Algorithms and Applications, 4th ed.; Pearson: Bengaluru, India, 2007.

43. Ashlock, D.; Brown, J.A. Fitness Functions for Searching the Mandelbrot Set. In Proceedings of the 2011 IEEE Congress on Evolutionary Computation, New Orleans, LA, USA, 5-8 June 2011; pp. 1108-1115.

44. Ashlock, D.; Jamieson, B. Evolutionary Exploration of Generalized Julia Sets. In Proceedings of the IEEE Symposium on Computational Intelligence in Image and Signal Processing, Honolulu, HI, USA, 1-5 April 2007; pp. 163-170.

45. Gdawiec, K.; Kotarski, W. Polynomiography for the polynomial infinity norm via Kalantari's formula and nonstandard iterations. Appl. Math. Comput. 2017, 307, 17-30. [CrossRef]

Publisher's Note: MDPI stays neutral with regard to jurisdictional claims in published maps and institutional affliations.

(C) 2020 by the authors. Licensee MDPI, Basel, Switzerland. This article is an open access article distributed under the terms and conditions of the Creative Commons Attribution (CC BY) license (http://creativecommons.org/licenses/by/4.0/). 